\title{
Comparison of Structural Properties of Pitches Prepared from Petroleum Refinery/Petrochemical Residues using NMR Spectroscopy
}

\author{
Manoj Srivastava*, Manoj Kumar, U. C. Agrawal and M. O. Garg
}

CSIR - Indian Institute of Petroleum, Dehradun 248 005, India

\begin{abstract}
Several petroleum pitches have been prepared by thermal treatment of various petroleum-derived residues such as clarified oil, aromatic extract and pyrolysis tars. These pitches were characterized physico-chemically (softening point, coking value, QI, \& TI) and instrumentally (NMR) and compared. Attempts have been made to correlate physicochemical properties of petroleum residues and pitches with their NMR structural parameters through regression analysis. Studies on high temperature in-situ ${ }^{1} \mathrm{H}$ NMR analysis of pitches have also been carried out. Structural characterization of petroleum residues and pitches is very useful for screening of petroleum residues and optimization of process variables for tailoring pitch properties for different end-use applications.
\end{abstract}

Keywords: Petroleum pitch, petroleum residues, mesophase, NMR.

\section{INTRODUCTION}

Today, petroleum refining industry is facing unprecedented challenges like declining crude quality and more severe product specifications. One main challenge before petroleum refiners/petrochemical producers is the effective utilization of petroleum residues produced during various petroleum refinery/petrochemical processes. Generally, these residues are used as blending streams for fuel oils but the market of fuel oil is shrinking. To fetch substantial money out of these low value petroleum residues, one way is to convert these petroleum residues into pitch.

Pitch is a widely used precursor for making many low volume but high cost 'industrial' and 'advanced' carbon materials [1]. Pitch is generally prepared by thermal treatment of petroleum/coal derived residues. The inherent complexity of petroleum residues increases the pitch complexity many more times. The properties of pitch are largely dependent on feed properties, thermal treatment temperature, residence time, pressure and additives used. The proper selection of these variables leads to formation of desired quality of pitches. The feed stock constituents and their reactivity greatly influence the properties of pitch. The knowledge of structural composition of isotropic pitch is also important for their conversion into mesophase pitch and thereafter production of various carbon materials namely needle coke, carbon fibers, meso carbon micro beads (MCMB) etc. NMR spectroscopy [2] is one of the powerful tools for structural characterization of feed stocks as well as pitches. It helps to quantify the different kinds of carbon and hydrogen atoms depending on their location and bonding within the molecules.

In the present study, various petroleum-derived residues were characterized and converted into pitches. The main

Address correspondence to this author at Indian Institute of Petroleum, Dehradun - 248 005, India; Tel +91 0135-2525772;

E-mail : manojs@iip.res.in objective of this work is to carry out a detailed study to correlate physico-chemical properties of feed stocks and pitches. High temperature in-situ NMR studies were also carried out to examine the mesophase formation behaviour in various isotropic pitches at high temperature. This will help to have a better understanding for selection of feed stocks for making 'mesophase pitches'.

\section{EXPERIMENTAL}

\subsection{Materials}

Several petroleum residues (PR) of different origin and nature namely clarified oil (PR-1), aromatic extract (PR-2) and pyrolysis tars (PR-3, PR-4) were used as feed stocks for making pitches. The characteristics of feed stocks are listed in Table 1. Free radical initiator benzoyl peroxide of 'Thomas Baker' make was used as an initiating agent for 'polymerization' and 'condensation' reactions. A commercially available petroleum derived pitch A-240 was used as a 'reference pitch'.

\subsection{Pitch Preparation}

Pitches were prepared by thermal treatment of feed stocks in a glass reactor equipped with a condenser to collect the distillate materials. The reactor was heated with an electric furnace and the temperature was monitored using a thermocouple. For each experiment about $100 \mathrm{gm}$ of feed stock was charged in the reactor and heated at a rate of $5^{\circ} \mathrm{C}$ $\min ^{-1}$ until the final thermal treatment temperature given in Table 2 was attained. In order to guarantee inert atmosphere, nitrogen was bubbled in the feed stocks. Different feed stocks were subjected to thermal treatment at different temperatures and for different residence periods. In one experiment, benzoyl peroxide was added as free radical initiator to initiate 'polymerization' and 'condensation' reactions. Pitch samples are denoted as P23, P37, P43, P58, P72-1, P72-2, P72-3, P72-4 prepared from different feed stocks as elaborated in the bottom of the Table $\mathbf{3}$. 


\subsection{Feed Stocks and Pitch Characterization}

All feed stocks and pitch samples were characterized for their physico-chemical properties by ASTM/IP standard test procedures. Pitches were characterized by determining their key properties like softening point (Mettler Toledo FP90, ASTM D-3104), coking value (ASTM D-2415), quinoline insolubles (ASTM D-2318), and toluene insolubles (ASTM D-4312) as given in Table 3.

\subsubsection{NMR Spectroscopy}

Structural analysis of feed stocks and pitch samples was carried out by computing average structural parameters derived from ${ }^{1} \mathrm{H}$ NMR spectroscopy. All spectra were recorded on a Bruker DRX 300 NMR spectrometer operating at $300.13 \mathrm{MHz}$. Chemical shifts were measured using TetraMethyl Silane (TMS) as an internal reference. All ${ }^{1} \mathrm{H}$ NMR spectra were recorded at $300^{\circ} \mathrm{K}$ using $10 \%(\mathrm{w} / \mathrm{w})$ sample solution in $\mathrm{CDCl}_{3}$ (99.8 atom \% from Sigma Aldrich). A total of 16 scans were acquired for each sample using $6.8 \mu \mathrm{S}$ pulse, a 12 second delay time between the scan and sweep width of $15 \mathrm{kHz}$. The cut-off point for different types of hydrogen [3] were as follows: $\mathrm{H}_{\mathrm{ar}}$ (aromatic hydrogen), 9.5$6.0 \mathrm{ppm} ; \mathrm{H}_{\alpha}$ (aliphatic hydrogen in $\alpha$ - position to an aromatic ring), 4.5-2.0 ppm; $\mathrm{H}_{\beta}$ (mainly aliphatic hydrogen in $\beta$ - position to an aromatic ring), $2.0-1.0 \mathrm{ppm} ; \mathrm{H}_{\gamma}$ (mainly aliphatic hydrogen in $\gamma$-position or farther to an aromatic ring) $1.0-0.5 \mathrm{ppm}$.

\subsubsection{High Temperature in-situ NMR Spectroscopy}

In-situ ${ }^{1} \mathrm{H}$ NMR measurements were performed to examine mesophase formation in isotropic pitches [4] at high temperature. All the spectra were fitted numerically to 'Lorentzian' and 'Gaussian' components. Total hydrogen from 'Gaussian' components was used to determine mesophase content.

\section{RESULTS AND DISCUSSION}

\subsection{Analysis of Results}

Physico-chemical properties of petroleum residues (feed stocks) are given in Table 1. Feed stock PR-1 is clarified oil from Fluid Catalytic Cracking (FCC) unit of petroleum refinery, PR-2 is aromatic extract, PR-3 and PR-4 are pyrolysis tars from naphtha cracking unit of two different petrochemical plants. The examination of physico-chemical properties showed that all feed stocks have density $>1.0000$ $\mathrm{gm} / \mathrm{ml}$. This suggests that all the feed stocks are aromatic in

Table 1. Characterization of Petroleum Residues (Feed Stocks)

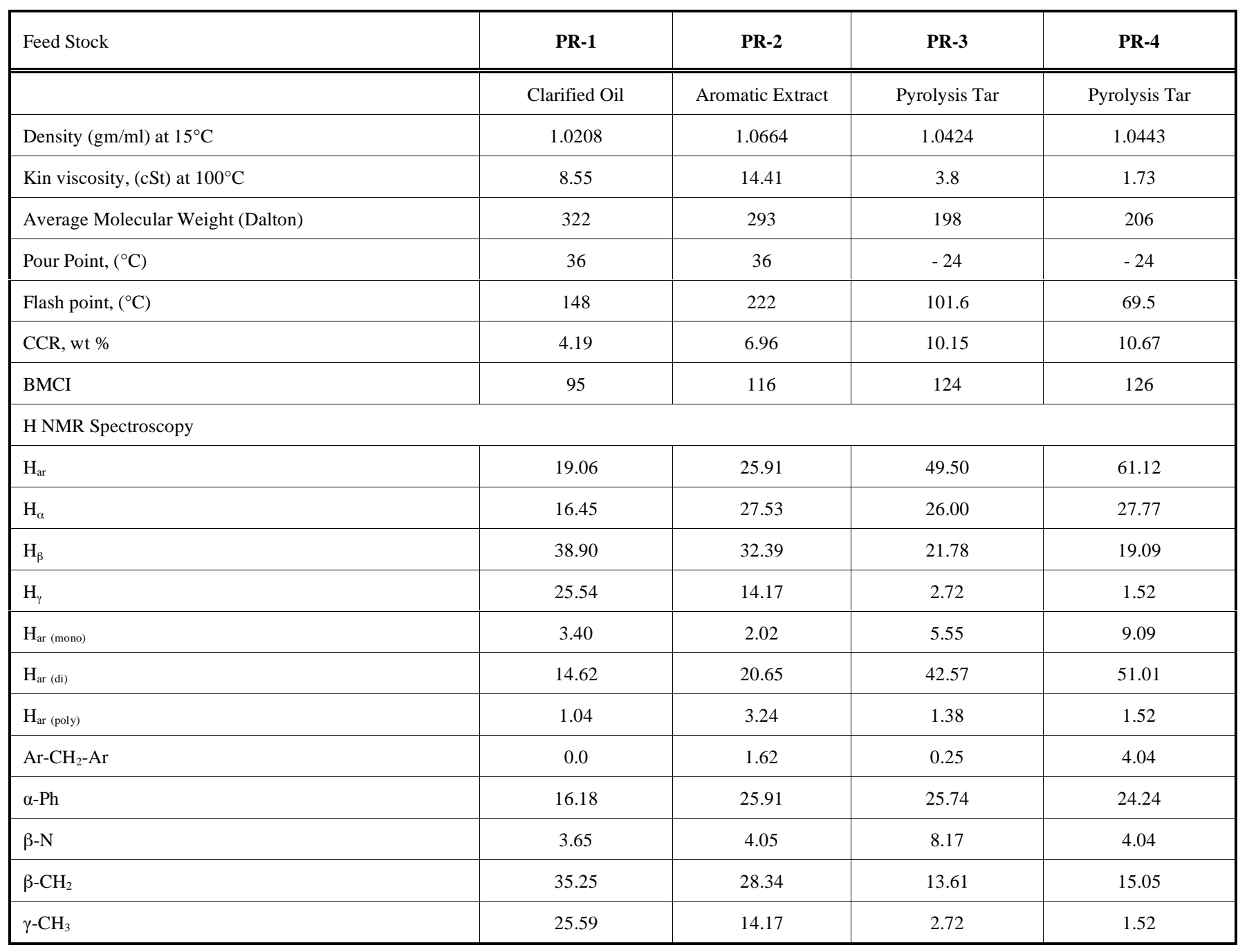


Table 2. Operating Conditions of Pitch Experiments

\begin{tabular}{|l|c|c|c|}
\hline Pitch & $\begin{array}{c}\text { Thermal Treatment } \\
\text { Temp. }\left({ }^{\circ} \mathbf{C}\right)\end{array}$ & $\begin{array}{c}\text { Thermal Treatment } \\
\text { Time (hr) }\end{array}$ & $\begin{array}{c}\text { Yield } \\
(\mathbf{w t} \%)\end{array}$ \\
\hline P58 & 400 & 30 & 36.00 \\
\hline P23 & 400 & 15 & 34.00 \\
\hline P37 & 340 & 6 & 41.26 \\
\hline P43* & 340 & 1.5 & 52.13 \\
\hline P72-1 & 340 & 3.0 & 50.00 \\
\hline P72-2 & 340 & 5.0 & 45.00 \\
\hline P72-3 & 340 & 7.5 & 40.00 \\
\hline P72-4 & 340 & & 35.00 \\
\hline
\end{tabular}

* Benzoyl peroxide added as initiating agent.

All experiments were carried out at atmospheric pressure.

nature and seem to be good for making petroleum pitches. High pour point of feed stocks PR-1 and PR-2 indicate the presence of paraffinic hydrocarbons in them. This fact is also supported by the fact that these two feed stocks have low conradson carbon residue (CCR) as a result of presence of more paraffinic hydrocarbons. The Bureau of Mines Correlation Index (BMCI) which is a measure of aromaticity shows that aromaticity is in the order of PR-1 $<$ PR-2 $<$ PR-3 $<$ PR-4. Since the feed stock rich in aromatics are more desirable for pitch production, on relative ranking pyrolysis tars (PR-3 and PR-4) are most suitable feed stocks followed by clarified oil (PR-1) and aromatic extract (PR-2). This fact is also validated by CCR value, which gives a direct indication of aromaticity in terms of carbon residue. Generally, feed stocks having CCR value $>5 \mathrm{wt} \%$ are more desirable for pitch production. This indicates that pyrolysis tars are welcome feed stocks for pitch production. NMR data of feed stocks also throw some light on structural composition of feed stocks. NMR data show that pyrolysis tars (PR-3 and PR-4) have more protons in aromatics i.e. they have more aromatic structures in comparison with clarified oil and aromatic extract (PR-1 \& PR-2). The clarified oil and aromatic extract contains substantial amount of paraffinic hydrocarbons as evident by $\beta-\mathrm{CH}_{2}$ value, which may be present as side chains on aromatic molecules. Some percentages of paraffin side chains in feed stocks are desirable because they provide cracking centers and generate free radicals for 'polymerization' and 'condensation' reactions [5].

The distribution of aromatics into mono-, di-, and polyaromatics shows that in all the feed stocks maximum percentage of aromatics exists in the form of di-aromatics. $\mathrm{H}_{\gamma}$ value indicate that paraffinic portion in clarified oil and aromatic extract is predominantly in the form of branched or iso- type structures. $\beta-\mathrm{N}$ represents the naphthenic type hydrocarbons. Such types of hydrocarbons are required for $\mathrm{H}$ - transfer reactions during pitch formation [6]. Clarified oil PR-1, aromatic extract PR-2 and pyrolysis tar PR-3 contain almost same percentage of naphthenic hydrocarbons. However, pyrolysis tar PR-4 contains a little higher percentage of $\beta-\mathrm{N}$.
The summary of experimental conditions of pitch experiments are presented in Table 2. Since, petroleum residue (feed stocks) PR-1 and PR-2 are high boiling materials, high thermal treatment temperature $\left(400^{\circ} \mathrm{C}\right)$ was selected for pitch preparation. For other pitches, a lower thermal treatment temperature $\left(340^{\circ} \mathrm{C}\right)$ was used.

Pitches P58, P23 and P37 \& P43 were prepared from clarified oil, aromatic extract, and pyrolysis tar respectively. Pitches P72-1, P72-2, P72-3, P72-4 were prepared from same pyrolysis tar under same thermal treatment temperature but giving different thermal treatment time. The experimental conditions for making pitches were fixed to get the softening point close to reference petroleum pitch, Ashland A-240. Properties of petroleum pitches are given in Table 3.

The physico-chemical properties of A-240 reference petroleum pitch show that it has softening point $115^{\circ} \mathrm{C}$, coking value $51.38 \mathrm{wt} \%$, quinoline insolubles (QI) $0.07 \mathrm{wt} \%$ and toluene insolubles (TI) $0.42 \mathrm{wt} \% .{ }^{1} \mathrm{H}$ NMR data of A240 showed that it has highest percentage of total aromatic protons $(53.98 \%)$ among all the pitches. The distribution of aromatics showed that most of the aromatics in the A-240 are present in the form of di-aromatics (39.80\%). Percentages of mono- and poly- aromatics in A-240 pitch are $(8.30 \%)$ and $(5.88 \%)$ respectively.

It has been observed that for similar softening point, pitches prepared from clarified oil and aromatic extract have higher coking values, quinoline insolubles (QI) and toluene insolubles (TI) than other pitches prepared from pyrolysis tars. The higher coking value, QI and TI of pitches P58 and P23 seems to be due to formation of poly-condensed aromatic hydrocarbons under severe experimental conditions both high thermal treatment temperature $\left(400^{\circ} \mathrm{C}\right)$ and long thermal treatment duration ( 30 and $36 \mathrm{hr}$ respectively). These poly- aromatic hydrocarbons are formed due to greater extent of 'polymerization' and 'condensation' reactions. This shows that more reactive molecular structures are present in them. This may be due to cracking of alkyl side chains results is generation of free radicals and formation of polycondensed aromatic structures. It was found that during thermal treatment, the percentage of poly-aromatic protons 
Table 3. Properties of Petroleum Pitches

\begin{tabular}{|c|c|c|c|c|c|c|c|c|c|}
\hline & A- 240 & P58 ${ }^{a}$ & $\mathbf{P} 23^{\mathrm{b}}$ & P72-1 ${ }^{\mathrm{c}}$ & P72-2 ${ }^{\mathrm{c}}$ & P72-3 & P72-4 & P37 ${ }^{\mathrm{d}}$ & $\mathbf{P 4 3}^{\mathrm{d}}$ \\
\hline QI (\% wt) & 0.07 & 0.04 & 0.02 & 0.02 & 0.02 & 0.03 & 0.07 & 0.04 & 0.05 \\
\hline $\mathrm{TI},(\% \mathrm{wt})$ & 0.42 & 1.78 & 6.20 & 0.48 & 0.59 & 0.67 & 0.94 & 0.87 & 0.78 \\
\hline $\mathrm{H}_{\mathrm{ar}}$ & 53.98 & 41.60 & 50.70 & 40.28 & 40.97 & 41.03 & 41.38 & 50.89 & 50.94 \\
\hline $\mathrm{H}_{\alpha}$ & 32.52 & 31.93 & 31.65 & 35.50 & 32.76 & 33.46 & 33.85 & 30.25 & 30.19 \\
\hline $\mathrm{H}_{\beta}$ & 11.32 & 21.43 & 14.01 & 20.28 & 22.05 & 20.72 & 20.37 & 15.66 & 15.57 \\
\hline $\mathrm{H}_{\gamma}$ & 2.08 & 5.04 & 3.64 & 3.94 & 4.51 & 4.78 & 4.39 & 3.20 & 3.30 \\
\hline $\mathrm{H}_{\mathrm{ar}(\mathrm{poly})}$ & 5.88 & 2.94 & 6.72 & 2.82 & 2.98 & 3.79 & 4.39 & 3.56 & 1.89 \\
\hline $\mathrm{Ar}-\mathrm{CH}_{2}-\mathrm{Ar}$ & 3.46 & 1.68 & 3.36 & 5.63 & 3.95 & 5.57 & 7.52 & 5.69 & 3.77 \\
\hline$\tilde{\alpha}-\mathrm{Ph}$ & 30.45 & 30.67 & 29.70 & 31.54 & 29.37 & 29.48 & 28.84 & 25.62 & 27.35 \\
\hline$\beta-\mathrm{N}$ & 4.50 & 6.72 & 6.16 & 7.32 & 7.91 & 7.57 & 7.52 & 6.41 & 6.13 \\
\hline$\tilde{\beta}-\mathrm{CH}_{2}$ & 6.82 & 14.71 & 7.85 & 12.96 & 14.14 & 13.15 & 12.85 & 9.25 & 9.44 \\
\hline$\tilde{\gamma}-\mathrm{CH}_{3}$ & 2.08 & 5.04 & 3.64 & 3.74 & 4.51 & 4.78 & 4.39 & 3.20 & 3.30 \\
\hline
\end{tabular}

Feed : a - Clarified Oil (PR-1), b - Aromatic Extract (PR-2), c - Pyrolysis Tar (PR-3), d- Pyrolysis Tar (PR-4).

in feed stocks (PR-1 \& PR-2) has increased to almost double in the respective pitches.

On comparing the pitches with each other, it was observed that pitches P37 and P43 prepared from pyrolysis tar (PR-4) are more aromatic in nature (total $\mathrm{H}_{\mathrm{ar}} 50.89$ \& $50.94 \%$ ) than the pitches prepared from 'clarified oil' and 'aromatic extract'. However, these pitches are less aromatic than reference pitch A-240 (total $\mathrm{H}_{\mathrm{ar}} 53.98 \%$ ). The clarified oil pitch P58 contains more paraffinic type hydrocarbons $\left(\mathrm{H}_{\beta}\right.$ $21.43 \%)$ than aromatic extract pitch $\mathrm{P} 23\left(\mathrm{H}_{\beta} 14.01 \%\right)$ and pyrolysis tar pitch $\mathrm{P} 43\left(\mathrm{H}_{\beta} 15.57 \%\right)$.

On comparing pitch P37 with P43 which were prepared under same experimental conditions except that during pitch P43 formation, a very small dose (1 wt $\%$ ) of benzoyl peroxide was added, it was seen that the physico-chemical properties and ${ }^{1} \mathrm{H}$ NMR data are very similar but the main deference is in thermal treatment time. The addition of small dose of free radical initiator (benzoyl peroxide) cuts down the thermal treatment time less than half for getting almost same quality of pitch $[7,8]$.

On comparing pitches P72-1, P72-2, P72-3 and P72-4 prepared by thermal treatment of pyrolysis tar (PR-4) for different thermal treatment time periods. There was a progressive increase in softening point, coking value, QI, TI, $\mathrm{H}_{\mathrm{ar}}$ and $\mathrm{H}_{\mathrm{ar}(\text { poly) }}$ as shown in Table 3. This supports the 'polymerization' and 'condensation' theory of aromatic hydrocarbons present in the petroleum residues (feed stocks) during formation of pitches.
Thermal treatment of isotropic pitches develops the 'mesophase' in the isotropic phase. The mesophase is a 'liquid-crystalline' phase. The formation of mesophase in isotropic pitches is an essential step for making a variety of carbon materials such as needle coke, mesocarbon micro beads (MCMB) and high modulus carbon fibers. The mesophase content in pitch is generally determined by optical microscopy. High temperature ${ }^{1} \mathrm{H}$ NMR spectroscopy is another effective tool to examine the transformation of isotropic pitch into mesophase pitches [9, 10]. In-situ high temperature ${ }^{1} \mathrm{H}$ NMR analysis was carried out on reference petroleum pitch A-240 and other pitches P23, P37, P43 and P58. Fig. (1) shows a plot of \% fluid components in pitches A-240, P23, P37, P43 and P58 against time held (0 - 60 minutes) isothermally at $470^{\circ} \mathrm{C}$. This shows that during one hour of experiment, as the heating period progresses the $\%$ of fluid (isotropic) components decreases or \% of rigid (mesophase) components increases. This indicates that at high thermal treatment temperature $\left(470^{\circ} \mathrm{C}\right)$ with the increase of thermal treatment time the 'isotropic' phase in the pitches is transformed into 'mesophase'.

Fig. (2) shows that Lorentzine components [ $\left.\mathrm{T}_{2} \mathrm{l}(\mu \mathrm{s})\right] \mathrm{Vs}$ time graph of various pitches. This shows that value of Lorentzine components which represent mobile or isotropic phase at 0 minute in Ashland A-240 pitch is $~ 500 \mu$ s, while in other pitches this value is $\sim 200-300 \mu \mathrm{s}$. After completion of heat treatment experiment for 60 minutes at $470^{\circ} \mathrm{C}$, it was found that the isotropic phase (Lorentzine) components were reduced to $\sim 80-140 \mu$ s in all pitches. 
These values indicate that a significant amount of isotropic phase has converted into mesophase in all pitches during heat treatment.

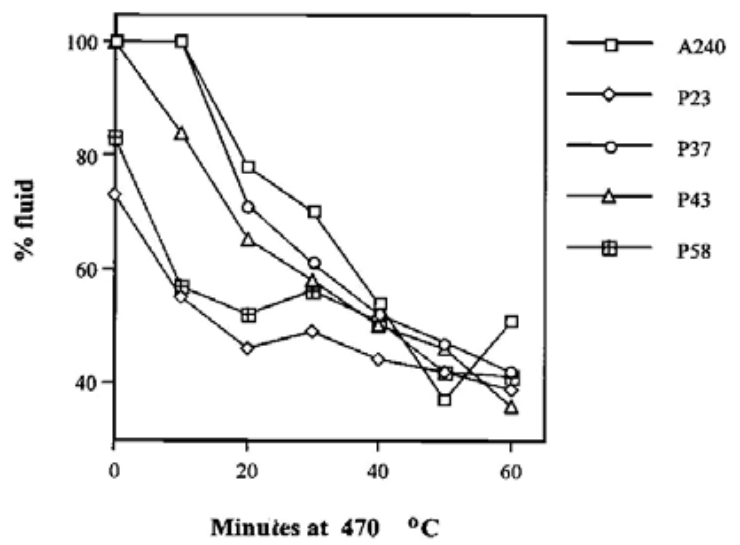

Fig. (1). Change of Fluidity of Pitches with Time.

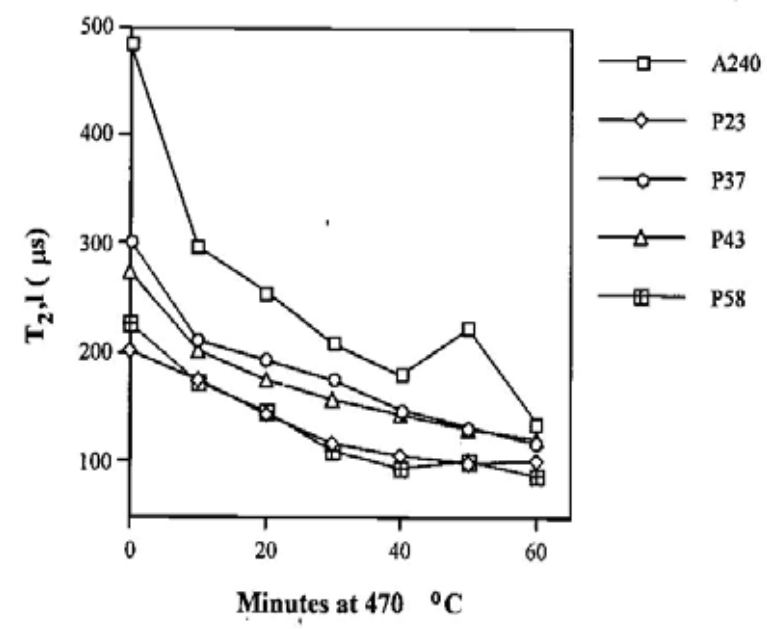

Fig. (2). Plot of $\%$ Isotropic Phase Vs Time at $470{ }^{\circ} \mathrm{C}$.

Fig. (3) shows that Gaussian components $\left[\mathrm{T}_{2} \mathrm{~g}(\mu \mathrm{s})\right] \mathrm{Vs}$ time graph of various pitches. This shows that value of Gaussian components which represent rigid or mesophase phase is $0 \mu \mathrm{s}$ at 0 minute of high temperature NMR experiment in pitch P43. The value of Gaussian components is also 0 upto 10 minutes of heating in Ashland A-240 and P37 pitches. This indicated that these three pitches are 'isotropic' in nature. Further, it was also observed that pitches P23 and P58 contain some rigid material at the onset of experiment at $470^{\circ} \mathrm{C}$. This may be due to formation of some mesophase which has already taken place in these pitches because these two pitches were prepared at higher temperature $\left(400^{\circ} \mathrm{C}\right)$ and by giving heat treatment for a longer period (> $30 \mathrm{hrs}$ ) as compared to other pitches which were prepared at a lower temperature $\left(340^{\circ} \mathrm{C}\right)$ and by giving heat treatment for a shorter period $(\leq 15 \mathrm{hrs})$. At the end of experiment (after 60 minutes), the value of Gaussian components of A-240 pitch is $\sim 50 \mu \mathrm{s}$, while for other pitches this value is $\sim 30-35 \mu$ s. These values indicate that mesophase formation behaviour of A-240 pitch is different from other pitches.

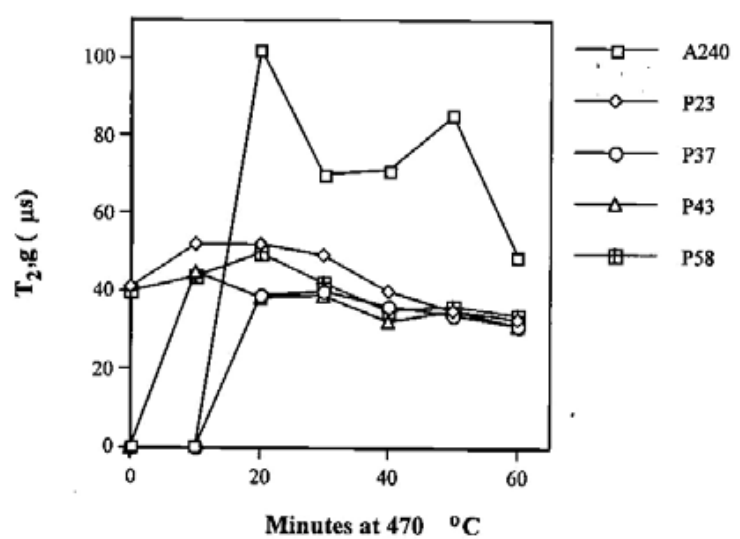

Fig. (3). Plot of $\%$ Mesophase Content Vs Time at $470^{\circ} \mathrm{C}$.

Fig. (4a, b) showed the deconvoluted spectra of A-240 at $470^{\circ} \mathrm{C}$ at 0 and 60 minutes hold time. These figures showed that on increasing thermal treatment time anisotropy (mesophase) in pitch increases.

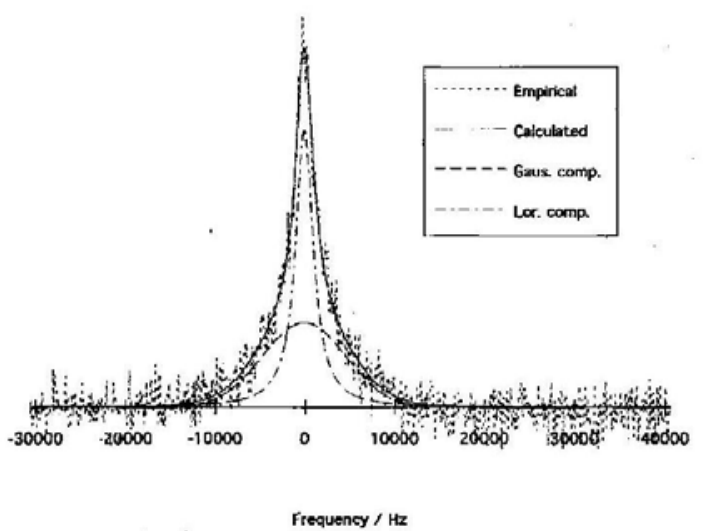

Fig. (4). a: Deconvoluted Spectrum of A-240 at $470^{\circ} \mathrm{C}$ (0 minute Hold Time).

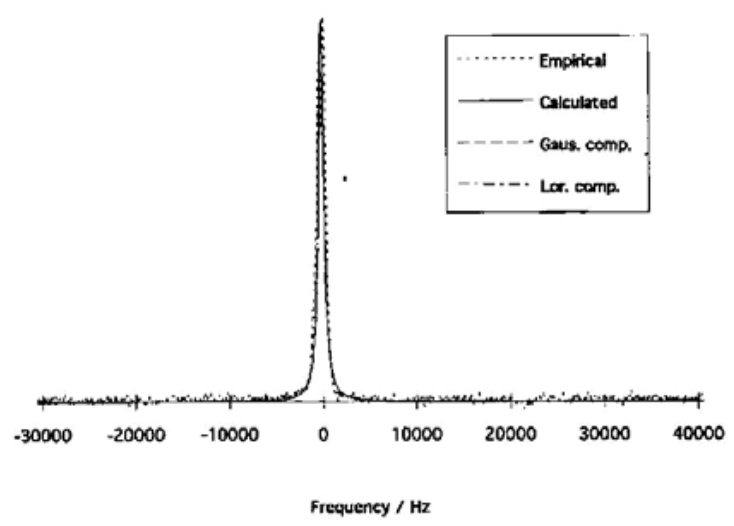

Fig. (4). b: Deconvoluted Spectrum of A-240 at $470^{\circ} \mathrm{C}$ (60 minutes Hold Time).

\subsection{Regression of Data}

Regression is used in a wide variety of applications that seek to analyze how a single dependent variable is affected by the value of one or more independent variables. The 
multiple linear regression model is the most commonly applied statistical technique for relating a variable $\mathrm{Y}$ to a set of $\mathrm{N}$ explanatory variables $\mathrm{X}_{1}, \mathrm{X}_{2} \ldots \ldots . \mathrm{X}_{\mathrm{n}}$. The liner model to be estimated is given by:

$\mathrm{Y}=\mathrm{a}_{0}+\mathrm{a}_{1} \mathrm{X}_{1}+\mathrm{a}_{2} \mathrm{X}_{2}+\ldots \ldots \ldots \mathrm{a}_{\mathrm{N}} \mathrm{X}_{\mathrm{N}}+\mathrm{U} \ldots \ldots \ldots \ldots \ldots . . .(1)$

Where $a_{0}$ is a constant and $a_{1}, a_{2} \ldots \ldots . a_{N}$ are partial regression coefficients. $U$ is an error term representing all other factors which influence Y.

In the present study some physico-chemical properties of different petroleum pitches such as softening point and coking value are correlated with their respective various average structural parameters like $\mathrm{H}_{\mathrm{ar}}, \mathrm{H}_{\mathrm{ar}(\mathrm{mono})}, \mathrm{H}_{\mathrm{ar}(\mathrm{di})}$, $\mathrm{H}_{\text {ar(poly) }}, \mathrm{H}_{\alpha}, \mathrm{H}_{\beta}$ and $\mathrm{H}_{\gamma}$ derived from ${ }^{1} \mathrm{H}$ NMR spectra. These correlations allow minimization of lengthy experimental tests and maximization of obtainable information. All the correlation in this study was developed using multivariate regression analysis on Pentium 4 compatible computing system.

The following equations were developed for softening point and coking value prediction. A simple multiple regression analysis of softening point, coking value and ${ }^{1} \mathrm{H}$ NMR data were conducted and respective equation of their correlation obtained are:

\section{- Coking Value $=0.2693 \mathrm{X}$ Softening Point +10.88}

In this equation, $\mathrm{R}^{2}$ value is 0.98268 , standard error is 1.016 , $\Delta$ between experimental and predicted value is 0.97

- Coking Value = $1402.302-13.0093\left(\mathrm{H}_{\mathrm{ar}}\right)-14.8954\left(\mathrm{H}_{\alpha}\right)$ $14.8807\left(\mathrm{H}_{\beta}\right)-3.2244\left(\mathrm{H}_{\gamma}\right)$

In this equation, $\mathrm{R}^{2}$ value is 0.8642 , standard error is $3.4, \Delta$ between experimental and predicted value is 4.4 maximum.

- Softening Point. $=8.657\left(\mathrm{H}_{\mathrm{ar}}\right.$ mono $)+1.771\left(\mathrm{H}_{\mathrm{ar}} \mathrm{di}\right)+$ $1.158\left(\mathrm{H}_{\text {ar poly }}\right)+106.4917$

In this equation, $\mathrm{R}^{2}$ value is 0.998239 , standard error is $0.485575, \Delta$ between experimental and predicted value is 0.3 maximum

\section{CONCLUSIONS}

1) Physico-chemical and NMR characterization of petroleum residues showed that pyrolysis tars (PR-3 \& PR-4) are most suitable feed stocks for pitch making due to their higher aromaticity (BMCI).

2) The pitch properties are greatly dependent on feed stock's molecular composition.

3) In the 'clarified oil' and 'aromatic extract', a good amount of molecular compounds present are of paraffinic type and are in the form of aliphatic side chains attached to aromatic molecules (PR 1 and PR 2). Hence, they take longer thermal treatment time (>30 hrs) in converting petroleum pitches of desired quality as compared to pyrolysis tars which are aromatic in nature.

4) Petroleum pitches P58 and P43 produced from clarified oil and pyrolysis tar respectively are very similar to reference pitch A - 240 in properties. This showed that by proper selection of feed stocks and experimental conditions pitches of desired quality can be prepared.
5) During thermal treatment of feed stocks, aliphatic side chains attached to aromatic molecules are cracked down and resulting aromatic molecules undergo polymerization and condensation reactions which is evident by increasing softening point, coking value, quinoline insolubles (QI) and toluene insolubles (TI) in pitches of same series namely P72-1, P72-2, P72-3 and P72-4.

6) It was found that the rate of sluggish polymerization and condensation reactions in pitch formation can be enhanced by adding small dose (1 wt $\%$ ) of benzoyl peroxide as free radical initiator. Benzoyl peroxide is a very effective initiating agent for this purpose. For almost same quality and yield of pitches, addition of benzoyl peroxide reduces the thermal treatment time less than half which can make the pitch process more energyefficient.

7) The regression analysis of physico-chemical properties (softening point and coking value) and average structural NMR parameters $\left(\mathrm{H}_{\mathrm{ar}}, \mathrm{H}_{\mathrm{ar}(\mathrm{mono})}, \mathrm{H}_{\mathrm{ar}(\mathrm{di})}, \mathrm{H}_{\mathrm{ar}(\text { poly })}, \mathrm{H}_{\alpha}, \mathrm{H}_{\beta}\right.$ and $\mathrm{H}_{\gamma}$ ) of pitches show good correlations.

8) In-situ high temperature ${ }^{1} \mathrm{H}$ NMR spectroscopy shows that on heating upto $470^{\circ} \mathrm{C}$, all the pitches produce $\sim 30$ $35 \%$ rigid materials (mesophase or liquid-crystalline state) while A-240 produces more rigid materials ( 50 $\%)$.

9) In-situ NMR spectroscopy also shows that A-240 pitch exhibit a different mesophase formation behaviour as compared to other petroleum pitches.

\section{CONFLICT OF INTEREST}

None declared.

\section{ACKNOWLEDGEMENTS}

Authors of this paper thank Director of the CSIR-Indian Institute of Petroleum, Dehradun for giving permission to publish this research paper. Authors also wish to thank Dr S.S. Ray for carrying out ${ }^{1} \mathrm{H}$ NMR analysis of pitch samples. Authors also wish to thank Dr I.D. Singh and Prof C. E. Snape for arranging in-situ ${ }^{1} \mathrm{H}$ NMR measurements of our pitch samples.

\section{REFERENCES}

[1] I. Mochida, Y. Korai, C.H. Ku, F. Watanabe, and Y. Saki, "Chemistry of synthesis, structure, preparation and application of aromatic-derived mesophase pitch", Carbon, vol. 38, pp. 305-328, 2000

[2] C. Diaz, and C.G. Blanco, "NMR: A Powerful Tool in the Characterization of Coal Tar Pitch", Energy Fuels, vol. 17, pp. 907-913, 2003.

[3] H. Singh, M. Srivastava, I.D. Singh, and T.S.R. Prasada Rao, "Feasibility of Making Electrode Pitches (Impregnating Type) From Petroleum Feed Stocks (Phase Ii - Experimental Studies [1])”, IIP Report No. LBA: 93. Graphite India Limited, India, 1993.

[4] J.M. Andrésen, Y. Martín, S.R. Moinelo, M.M. Maroto-Valer, and C.E. Snape, "Solid state ${ }^{13} \mathrm{C}$ NMR and high temperature ${ }^{1} \mathrm{H}$ NMR determination of bulk structural properties for mesophasecontaining semi-cokes prepared from coal tar pitch", Carbon, vol. 36, no. 7-8, pp. 1043-1050, 1998.

[5] M. Srivastava, S. Gupta, M. K. S. Aloopwan, I.D. Singh, M. Anwar, and M.O. Garg, "Advances in carbon materials - Indian Scenario", In: O. P. Bhal and T. L. Dhami, Eds. Proceeding of the National Conference on Carbon, New Delhi, India, Oct 28,29 1999, pp. 192. 
[6] L.R. Rudnic, and L.G Galya, "Structural and chemical changes during coking of two petroleum residua: hydrogen and carbon distribution of liquid products", Energy Fuels, vol. 5, pp. 733-738, 1991.

[7] H. Singh, M. Srivastava, I.D. Singh, and T.S.R Prasada Rao, "Improved Technology for Making Petroleum Base Impregnating Type Electrode Pitch - Process Demonstration Experiments", IIP Report No. RTD (LBA):20:95, Graphite India Limited, India, 1995.

[8] S. Gupta, M. Srivastava, and H. Singh, "Mechanism of conversion of heavy aromatic feedstocks into petroleum pitch by thermal soaking reactions, Erdol Erdgas Kohle, vol.127, no. 5, pp. 204-206, 2011.

[9] T. Yokono, N. Takahashi, T. Kaneko, and Y. Sanada, "High temperature ${ }^{13} \mathrm{C}$ NMR study on mesophase pitch", Fuel, vol. 69, pp. 796-798, 1990.

[10] K. Azami, S Yamamoto, T. Yokono, and Y. Sanada, "In-situ monitoring for mesophase formation processes of various pitches by means of high temperature ${ }^{13} \mathrm{C}-\mathrm{NMR} "$, Carbon, vol. 29 , no. 7, pp. 943-947, 1991.

Received: December 23, 2011

Revised: April 05, 2012

Accepted: April 10, 2012

(c) Srivastava et al.; Licensee Bentham Open.

This is an open access article licensed under the terms of the Creative Commons Attribution Non-Commercial License (http://creativecommons.org/licenses/by-nc/3.0/) which permits unrestricted, non-commercial use, distribution and reproduction in any medium, provided the work is properly cited. 